DOI: $10.2478 /$ ace-2013-0031

\title{
RESEARCH ON A LABORATORY TECHNIQUE FOR TIRE-PAVEMENT NOISE ASSESSMENT OF ASPHALT MIXES
}

\author{
K.J. KOWALSKI ${ }^{1}$, T. DARE ${ }^{2}$, R.S. MCDANIEL ${ }^{3}$, J. OLEK ${ }^{4}$, R. BERNHARD ${ }^{5}$
}

Communication noise is classified as one of the pollutions for the current environment. Experimental techniques to measure tire-pavement noise generation from asphalt pavements in the laboratory have been limited. A series of experiments were conducted on six different asphalt mixtures to determine if Purdue University's Tire-Pavement Test Apparatus (TPTA) could be used to overcome these limitations. The procedure produced samples with low tire-pavement noise; however, the air void contents of the samples were higher than designed. Despite these difficulties, the sample preparation technique and the TPTA testing protocol were shown to offer an effective approach for quick laboratory assessment of tire-pavement noise characteristics of hot mix asphalt pavements at a substantially reduced cost compared to field testing.

Keywords: noise, tire-pavement interaction, tire/pavement interaction, stone matrix asphalt (SMA), porous friction course (PFC), dense graded asphalt (DGA), asphalt pavement

\section{INTRODUCTION}

The volume of commercial goods and people transported over the network of roadways and highways in the $21^{\text {st }}$ Century is higher than ever. One of the undesirable effects of these transportation activities is traffic noise, which causes annoyance to drivers and passengers, as well as to people and animals living near the highways. It has been reported (Fleming et al. [1], Miller [2]) that nearly every person living in the United States is, to some extent, affected by transportation-related noise.

Various strategies can be used to limit vehicle noise, including barriers, technological solutions and legal regulations (Tracz, BohatKiewicz [3]). When designing a pavement surface, engineers must strive to balance several parameters, including load

1 Warsaw University of Technology, Faculty of Civil Engineering, office 540, al. Armii Ludowej 16, 00-637, Warsaw, Poland, k.kowalski@il.pw.edu.pl, (Corresponding author).

2 Applied Research Laboratory, Pennsylvania State University, USA, tp10@psu.edu

3 North Central Superpave Center, USA rsmcdani@purdue.edu

4 Professor of Civil Engineering and Director of the North Central Superpave Center, Purdue University,USA, olek@purdue.edu

5 University of Notre Dame, USA, rbernhar@nd.edu 
capacity, durability, ride quality, construction and maintenance costs, as well as safety and traffic noise. Tire-pavement noise is related to the surface texture and to the internal structure of the surface layer (including air void content, distribution, and tortuosity) (GARDZIEJCZYk [4]).

Currently, many researchers are working on "quiet" pavements as an alternative to noise barriers surrounding the roads. Much progress has been made in the prediction of tire-pavement noise based on measured pavement texture (KuIJPERS, BLOKLAND [5]), and good laboratory methods exist for the prediction of the mechanical properties of asphalt pavements. However, so far there is no comprehensive method for the prediction of field tire-pavement noise levels based on laboratory testing.

\subsection{Laboratory Measurements of Tire-Pavement Noise on Asphalt Pavements}

Tire-pavement noise mechanisms can generally be separated into those related to noise generation and those related to noise propagation. Both groups of mechanisms require different treatment and different testing methods. Propagation from the source to the pavement's edge can be measured in the laboratory using a variety of different techniques, including sound-absorption testing with an impedance tube and grazing incidence impedance testing (Taherzadeh, Attenborough [6], Imase et al. [7], Crocker et al. [8]). Techniques for measuring tire-pavement noise generation in the laboratory, however, have been limited to drum testing methods.

A number of laboratory drum testing methods have been used to study tire-pavement noise generation (e.g. German Road Laboratory (BASt) drum) (SANDBERG, EJSMONT [9]). It has been shown that laboratory drum measurements on surfaces that replicate actual roadway surfaces can be used to predict in-service far-field noise levels (SANDBERG, EJSMONT [10]). Other studies on this phenomenon recently were conducted by the Belgian Research Center for Cement Industry. However, there are challenges presented by asphalt pavements that are not present with portland cement concrete or epoxy pavements. For example, when using laboratory drums with pavement rotating around a stationary tire, drum surfaces are usually limited to one or two idealized surfaces because an entire drum of pavement must be fabricated (NILSSON [11]). In addition, centrifugal forces and potential creep of the asphalt mixture also limit the use of a realistic asphalt pavement on a rotating drum.

Purdue University's Tire-Pavement Test Apparatus (TPTA) has been specifically designed to address most of the issues involved in laboratory testing of tire-pavement noise generation on asphalt pavements. Instead of using a rotating drum and a stationary tire, the TPTA uses a pair of tires rolling around a stationary drum of pavement. Its advantages over other laboratory drum techniques are that pavement samples can fabricated from actual field construction materials and that accurate measurements can be conducted with pavement samples as small as $2 \mathrm{~m}$ long and $0,4 \mathrm{~m}$ wide. In addition, up to six different pavement samples can be tested simultaneously, and different pavement samples can be mounted on the TPTA in a matter of minutes. The TPTA has been used 
to study various tire-pavement noise generation phenomena on a variety of pavements (Bernhard et al. [12], Dare et al. [13], Olek et al. [14], Olek et al. [15], Scofield, Smith [16]). However, it has previously been used only for a very limited number of noise measurements on asphalt pavements.

\section{Problem Statement and Objectives}

The main purpose of this research was to explore the use of the TPTA as a method of measuring noise generated by various hot mix asphalt (HMA) pavements in the laboratory. A second purpose was to use measurements conducted on HMA pavement samples with the TPTA to attempt to predict noise levels under highway conditions.

\section{Test Program}

The test program of this study included preparation of six different HMA mixtures, fabrication of test specimens and tire-pavement noise testing using the Tire-Pavement Test Apparatus (TPTA).

\subsection{Materials}

The HMA mixtures used in the study included: one porous friction course (PFC), one stone matrix (or mastic) asphalt (SMA) and four different Superpave mixtures (dense graded asphalt, DGA). The two DGA mixtures had nominal maximum aggregate sizes (NMAS) of 9,5 $\mathrm{mm}$ with fine and coarse gradations while the other two DGA mixtures had NMAS of $19 \mathrm{~mm}$ with fine and s-shaped gradations. Since it is well-known that the macrotexture of the surface will influence tire-pavement noise generation (RASMUSSEN et al. [17], Rasmussen et al. [18], Cesbron et al. [19]), the mixtures selected for testing represented a wide range of textures of common asphalt pavements. Aggregate blend gradations of the asphalt mixes tested in this study are shown in Figure 1.

The DGA and SMA mixes were designed for the same air void content of $4 \%$ while the PFC was designed for an air void content of 22\%. The Superpave Gyratory Compactor was used during the mix design process to compact the specimens. The design gyration levels were 100 for the SMA and DGA and 20 for the PFC.

The details of material type, quantity and volumetric data of the asphalt mixes are shown in Table 1. Steel slag aggregate, considered a high-friction aggregate, was used in different proportions in all the mixes and was blended with carbonate aggregate (dolomite). The binder content (by weight) was the same $(5,7 \%)$ for two of the $9,5 \mathrm{~mm}$ DGA mixtures and SMA mixture. It was slightly lower $(5,5 \%)$ for the PFC mixture. As expected, the $19 \mathrm{~mm}$ DGA mixes had lower binder contents $(5,4 \%$ for s-shaped gradation and $4,2 \%$ for fine gradation). In terms of volume, however, the binder contents 
of the SMA and PFC mixes were higher than that of the DGA mix $(17,3-17,7 \%$ vs. $11,1-14,9 \%)$, since more of the dense steel slag aggregate was used in those mixes.

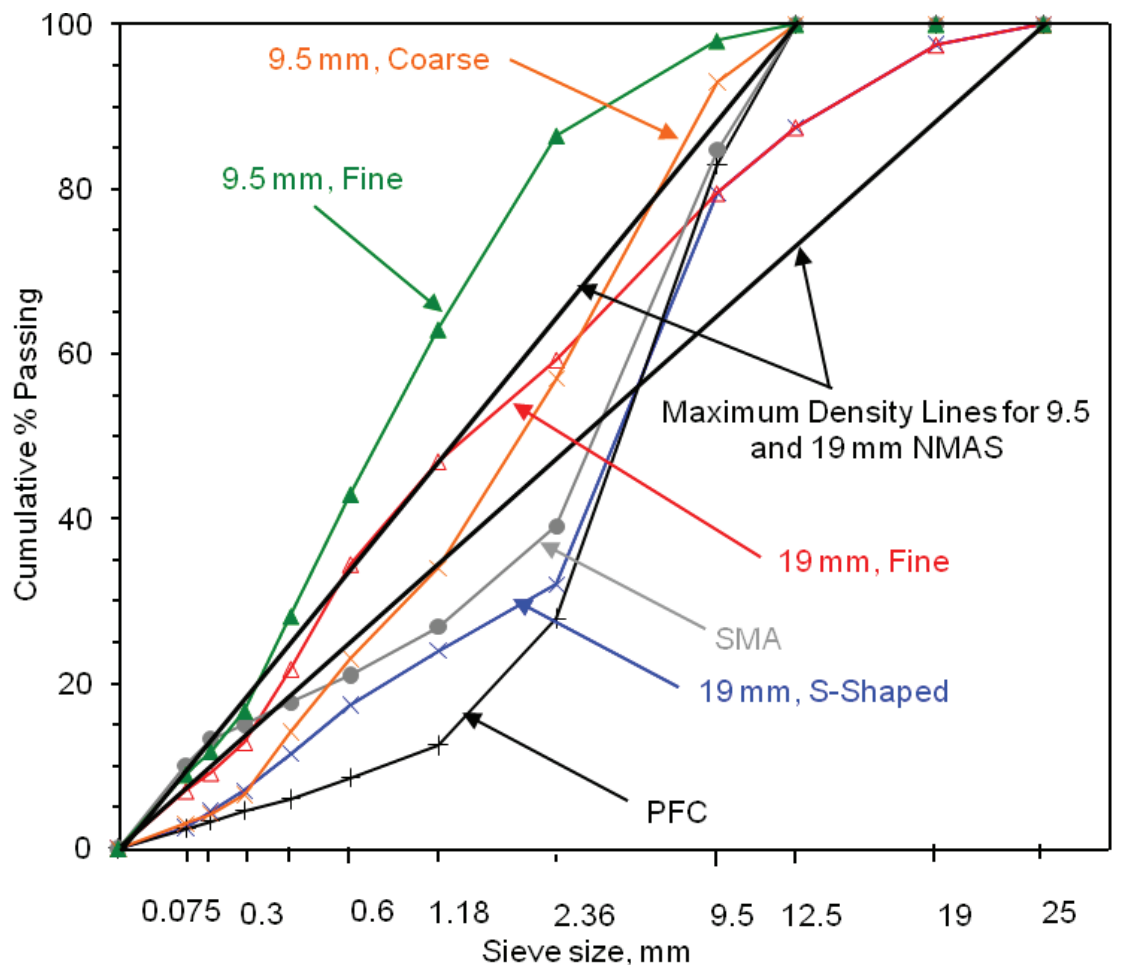

Fig. 1. Mixture gradations

Table 1

Material type, quantity and volumetric data of asphalt mixes.

\begin{tabular}{|c|c|c|c|c|c|c|}
\hline HMA Type & \multicolumn{4}{|c|}{ Superpave (DGA) } & SMA & PFC \\
\hline Gradation Type & Coarse & Fine & Fine & S-shaped & SMA & PFC \\
\hline NMAS, mm & 9,5 & 9,5 & 19 & 19 & 12,5 & 12,5 \\
\hline Label & $\begin{array}{c}9,5 \mathrm{~mm}, \\
\text { coarse }\end{array}$ & $\begin{array}{c}9,5 \mathrm{~mm}, \\
\text { fine }\end{array}$ & $\begin{array}{c}19 \mathrm{~mm}, \\
\text { fine }\end{array}$ & $\begin{array}{c}19 \mathrm{~mm}, \\
\text { S-Shaped }\end{array}$ & PFC & SMA \\
\hline Binder Content, $\mathrm{P}_{\mathrm{b}}, \%$ by wt., & 5,7 & 5,7 & 4,2 & 5,4 & 5,7 & 5,5 \\
\hline Binder type & PG 64-22 & PG 64-22 & PG 64-22 & PG 64-22 & PG 76-22 & PG 76-22 \\
\hline $\begin{array}{c}\text { Binder Content, \% by vol. } \\
\text { of mix }\end{array}$ & 14,9 & 14,9 & 11,1 & 14,1 & 17,7 & 17,3 \\
\hline
\end{tabular}


Table 1

\begin{tabular}{|c|c|c|c|c|c|c|}
\hline $\begin{array}{c}\text { Coarse Aggregate: Steel } \\
\text { Slag, \% }\end{array}$ & 20 & 20 & 20 & 20 & 80 & 90 \\
\hline $\begin{array}{c}\text { Coarse Aggregate: Dolomite, } \\
\%\end{array}$ & 51 & 20 & 35 & 59 & 10 & 10 \\
\hline $\begin{array}{c}\text { Natural Sand, \% } \\
\begin{array}{c}\text { Manufactured Sand (Dolo- } \\
\text { mite), \% }\end{array}\end{array}$ & 12 & 50 & 37 & 11 & 10 & 10 \\
\hline $\begin{array}{c}\text { Mineral Filler, \% } \\
\text { Max. Theor. Spec. Grav., } \\
\mathrm{G}_{\mathrm{mm}}\end{array}$ & 2,65 & 2,66 & 2,69 & 2,65 & 3,15 & 3,19 \\
\hline
\end{tabular}

\subsection{Specimen Preparation}

The four DGA mixes were produced in the laboratory, while the SMA and PFC mixes were plant-produced and collected in the field during construction. At the time of specimen fabrication, mixes were reheated to the compaction temperature of $150^{\circ} \mathrm{C}$ and compacted into convex concrete molds (also called "concrete segments"). Six of these arc-shaped concrete molds fit around the circumference of the TPTA. Each mold has a rectangular trough formed in the outer surface to hold the asphalt mixture in place. The internal dimensions of these troughs, which also represent the dimensions of the asphalt layer, were as follows: $406 \mathrm{~mm}$ (width) x $1980 \mathrm{~mm}$ (length) x $76 \mathrm{~mm}$ (depth). Note that the reported length is not a planar dimension but the total length of the convex asphalt layer. For detailed information regarding the mold dimensions, refer to Figure 2.

In order to improve the adhesion of the HMA to the concrete molds, the molds were primed with PG 64-22 binder 24 hours prior to compaction. Both the roller (see the description in the next paragraph) and concrete molds were heated using lamps to prevent rapid cooling of the HMA during the compaction process (molds to about $55^{\circ} \mathrm{C}$, while roller to a temperature of $75^{\circ} \mathrm{C}$ ).

A specially-developed laboratory compaction procedure was used to prepare the specimens for this study. To compact the mixes, a static "rolling pin," with dimensions of $76 \times 28 \mathrm{~cm}$ (length $\mathrm{x}$ diameter), attached to a fork lift was used. Due to the convex arc of the sample, the load applied during the compaction could not be constant; a different load was applied at the top of the mold compared to the areas close to the ends. During the compaction, the estimated normal load was between 8,6 (top roller position) and $9,9 \mathrm{kN}$ (bottom roller position) based on static measurement of the applied load.

The initial amount of mix to be compacted (typically 130-160 kg) was calculated based on the mold volume and HMA bulk specific gravity $\left(\mathrm{G}_{\mathrm{mb}}\right)$ corresponding to $7 \%$ air voids for the DGA and SMA mixtures, and $22 \%$ air voids for the PFC mixture, to simulate typical field compaction levels (referred to here as "expected" void levels). 
However, the actual amount of the mixture placed in the mold was somewhat smaller. Attempts to compact the full amount of mixture into the mold were unsuccessful, perhaps because of cooling of the mix. Further attempts to compact the mix to make it flush with the top of the mold, as intended, would have resulted in crushing the aggregate. Therefore, some mix had to be removed to produce the required smooth surface for testing.
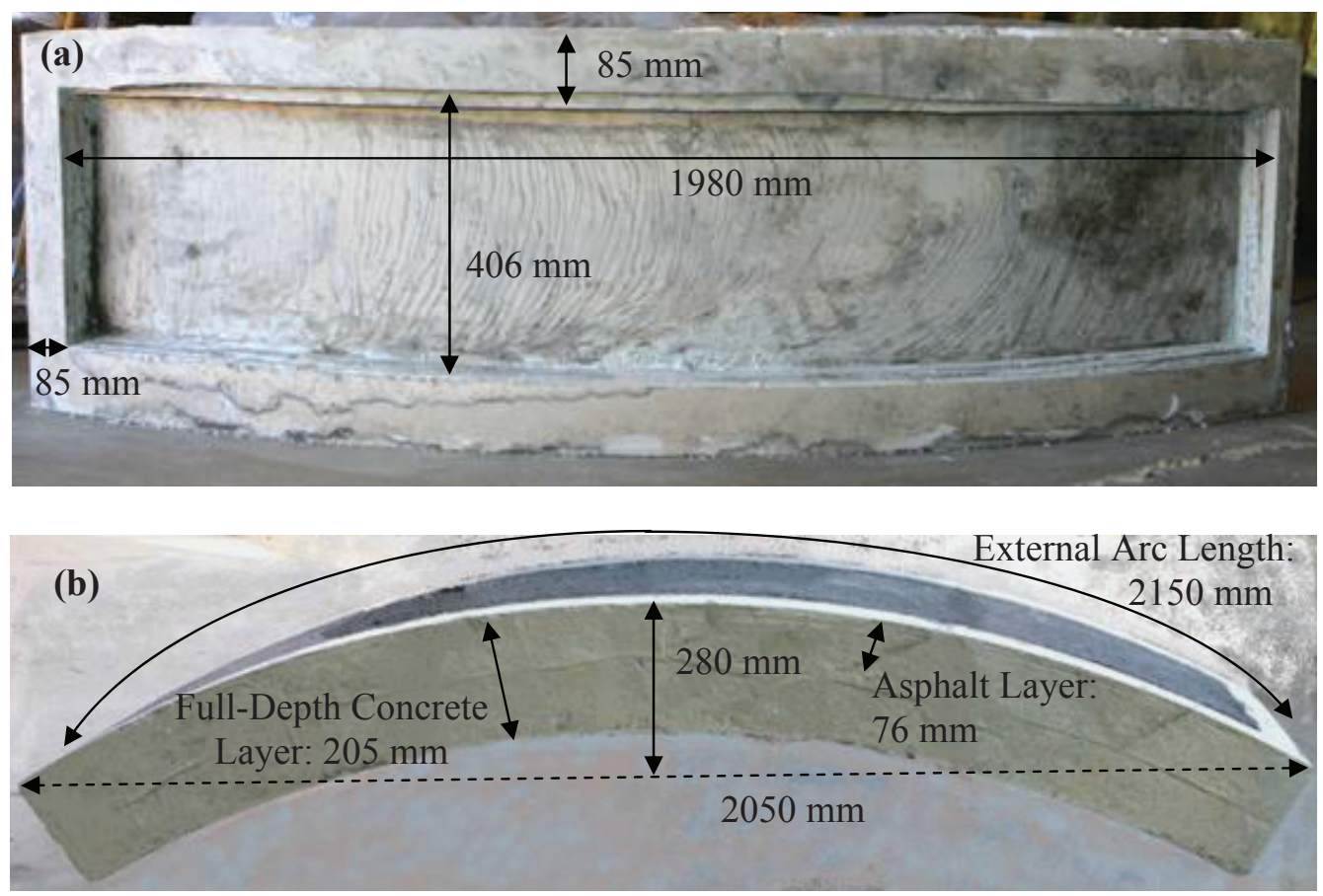

Fig. 2. Concrete molds used in the study: (a) top view showing only concrete mold with pree-form trough and (b) side view showing concrete mold filled with asphalt

Details of the compaction process are shown in Figure 3 (a-f). Compaction was accomplished in two stages. Each of the stages included mixture pre-densification and compaction. During the first stage, mixture was placed, tamped and roller-compacted in the middle part of the mold only. During the second stage, mixture was added to both ends (and to the middle section, if needed) of the mold and the entire length of the segment was compacted. This two stage process was applied in order to prevent the mixture from sliding down from the higher to the lower elevation along the curvature of the mold. Great attention was paid to obtaining as high and as consistent a density in the center of the segment as possible since that is where the noise measurements would be made. Rolling was continued until a smooth surface was obtained (which typically took about 4-8 passes of the roller). The typical rolling process took about 25 minutes 

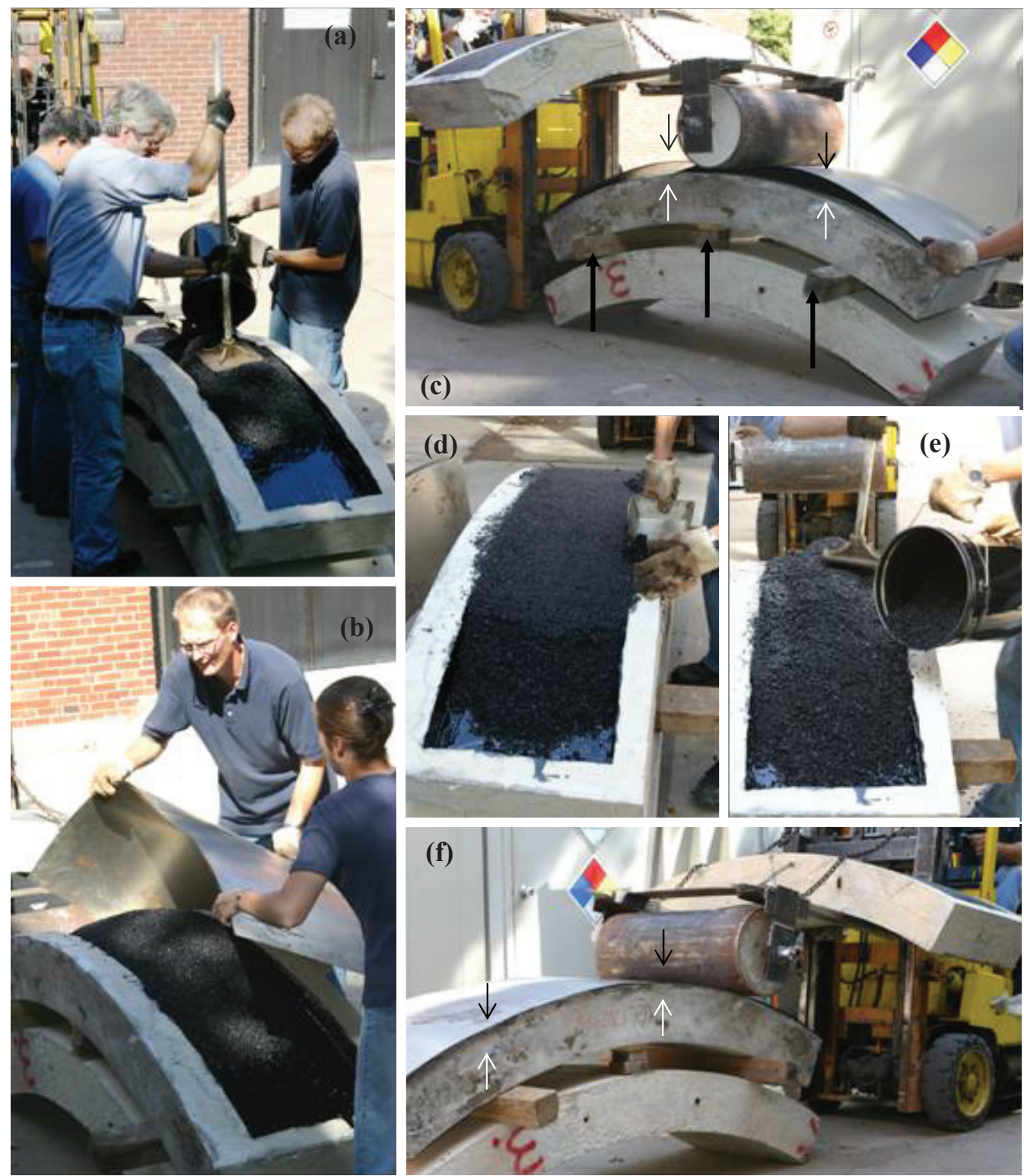

Fig. 3. Stages of the TPTA pavement sample compaction process: (a) first stage: pre-densification, (b) specimen before the first stage of compaction, (c) first stage: compaction, (d) removing mixture covering top of the concrete mold, (e) second stage: pre-densification and (f) second stage: compaction 
and the mix temperature was monitored during the entire compaction process. This process was developed through trial and error and was found to yield an acceptable (smooth) surface profile. Although compaction of the convex sample could not fully simulate field operations, it is believed that the procedure utilized here simulated field compaction to a great extent (see section "Texture results"). Due to the length of the heating procedure utilized in this study, only one sample was prepared per day. Specific details of this procedure can be found elsewhere (KowaLsKi et al. [20])

\subsection{Laboratory Testing of Tire-Pavement Noise}

The TPTA is housed in a hemianechoic chamber to reduce background noise and reflections. As shown in Figure 4, the TPTA consists of a fixed drum and a rotating circular plate above the drum. Six curved pavement segments are mounted around the drum, forming a continuous ring of pavement, $4,1 \mathrm{~m}$ in diameter. Two arms are attached to the rotating plate, and a wheel assembly is suspended from the end of each arm. During testing, the rotating plate causes the wheels to roll along the outside of the pavement ring. The TPTA can achieve speeds of up to $48 \mathrm{~km} / \mathrm{h}$, and the speed is accurate to within $0,5 \mathrm{~km} / \mathrm{h}$. The normal load on each tire can be adjusted from $0-4,4 \mathrm{kN}$. For the present study, the normal load was set at 2,67 kN. One standard and two commercially available tires (often used in tire-pavement noise studies in the US) were used for this study: an ASTM Standard Reference Test Tire (P225/60R16 97S), Goodyear Aquatred III (P205/70R15 95T M+S) and Uniroyal Tiger Paw (P205/70R15 $95 \mathrm{~S} \mathrm{M}+\mathrm{S}$ ), called later in this paper as SRTT, Tire A and Tire B, respectively. Each tire was inflated to a pressure of $240 \mathrm{kPa}$.

On-Board Sound Intensity (OBSI) measurements were conducted on the TPTA. The microphones were arranged as prescribed in the AASHTO standard on OBSI [21]. Other specifications in the AASHTO standard, such as inflation pressure, vehicle speed, and some details of signal processing, were not followed, either because of limitations of the TPTA or because testing was conducted before the standard was finalized. The microphones used were a B\&K phase-matched intensity pair with a separation of $16 \mathrm{~mm}$. The measurements were recorded as A-weighted narrow-band sound intensity averaged over 100 passes of the testing arm of the TPTA. Each average represented a measurement time of $80 \mathrm{~ms}$, corresponding to the center of each pavement segment. The narrow-band intensity data were then summed into one-third octave bands centered from $400-4000 \mathrm{~Hz}$, and overall intensity levels were calculated by adding the narrowband intensity from $500-5000 \mathrm{~Hz}$. For this experiment, each pavement segment was tested separately, and a magnetic trigger was used to ensure that noise from the same section of pavement was measured with each pass of the testing arm. The trigger was set so that noise from the center portion of the desired sample was measured with each pass, as shown in Figure 4 (a).

OBSI measurements were made over several days of testing. Before each set of tests, the testing tire was warmed up by running the TPTA at $48 \mathrm{~km} / \mathrm{h}$ for 15 minutes, 

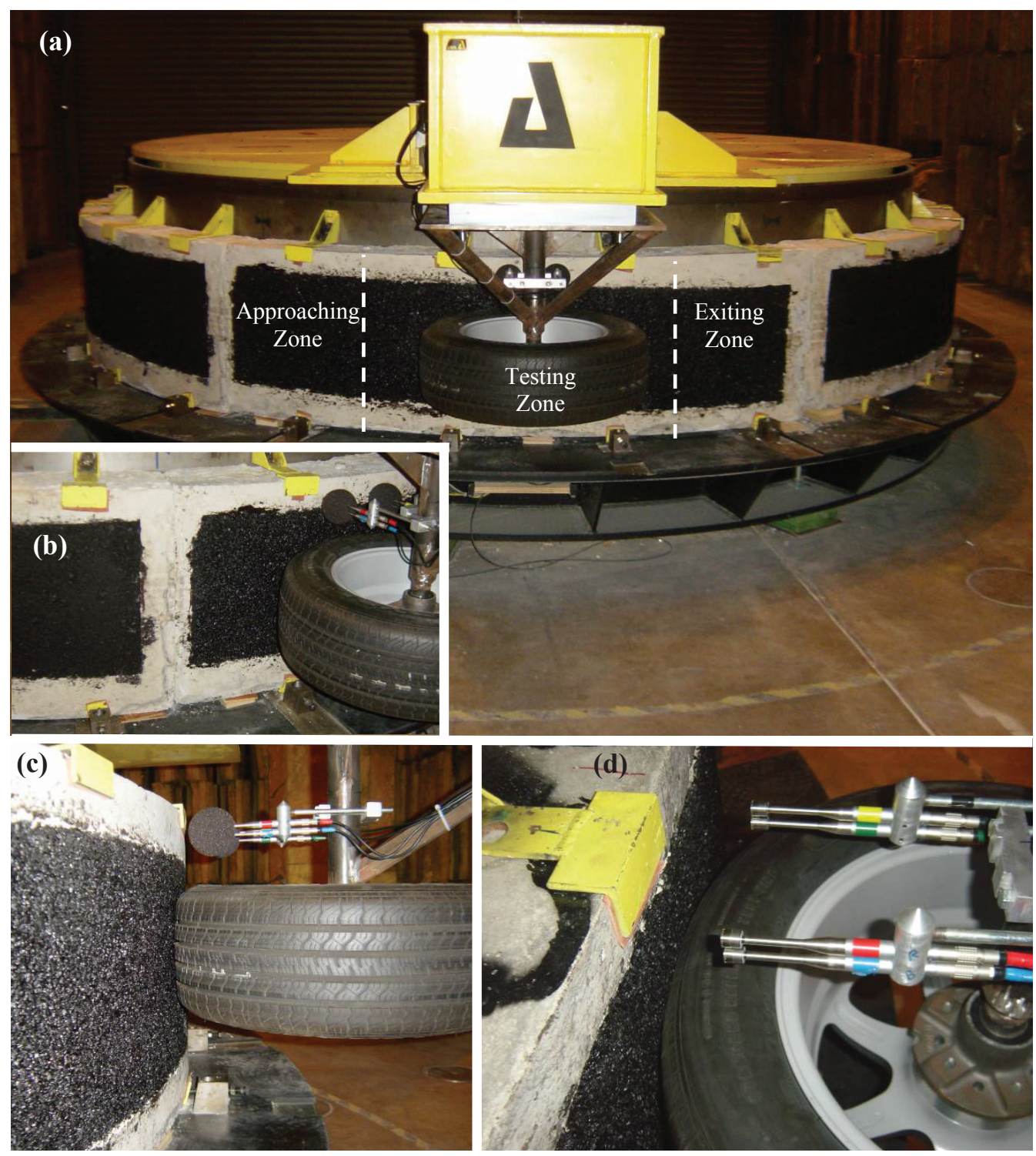

Fig. 4. TPTA during the operation: (a) general view, (b) transition zone between the specimens and microphone set-up, (c) side view and (d) oblique view (protective windscreens removed for the picture) 
the microphones were calibrated, and the ambient temperature was determined to be within $20 \pm 3^{\circ} \mathrm{C}$. During the first series of tests, the OBSI measurements on the six HMA samples were conducted on the newly-created specimens with the SRTT at $48 \mathrm{~km} / \mathrm{h}$. Before the measurements, the specimens were only exposed to short trial tests and the warm-up period, and therefore had very little wear. For the second series of tests, the same measurements were conducted, but there was slightly more wear on the samples because of the 2-3 hours of tests from the previous day. After the second series of tests, the TPTA was run at $48 \mathrm{~km} / \mathrm{h}$ for about five hours to wear off some of the asphalt coating the aggregate particles in the contact patch. After the wearing period, a third series of tests were conducted with all three test tires at 16,32 and $48 \mathrm{~km} / \mathrm{h}$ (due to space limitation, only results for $48 \mathrm{~km} / \mathrm{h}$ are shown here). Due to differences in the dimensions of the three tires, the centers of the wheel paths of the Tire A and Tire B tires were positioned about $2,5 \mathrm{~cm}$ above the center of the SRTT tire.

\subsection{Measurement of Pavement Parameters}

After noise testing on the TPTA was complete, air void contents were measured from core samples taken from each of the six specimens. For those core samples $(152 \mathrm{~mm}$ diameter), the bulk specific gravity $\left(\mathrm{G}_{\mathrm{mb}}\right)$ was determined following ASTM D 6752 (2004) using the CoreLok apparatus. Based on this $\mathrm{G}_{\mathrm{mb}}$ and the previously determined maximum theoretical specific gravity $\left(\mathrm{G}_{\mathrm{mm}}\right)$, the air void content was then calculated for each specimen.

In addition, using the Circular Track Meter (CTM, ASTM E2157), mean profile depth (MPD) of the test specimen was also measured after the noise testing.

\section{Test Results and Discussions \\ 4.1. Void Content and Texture Results}

The measured and expected air void contents of each sample are shown in Figure 5. The four DGA samples and the SMA were expected to have air void contents of about $7 \%$, but the actual measured air content was between 14 and $23 \%$ for these samples. For the PFC sample, the expected air void content was $22 \%$, but it was measured to be $26 \%$. This is an indication that the samples were not adequately compacted during the fabrication process, and that the compaction method may need to be further refined. MPD for each sample is shown in Figure 6. As expected, the PFC had the highest MPD, followed by the SMA and the four DGA samples. 


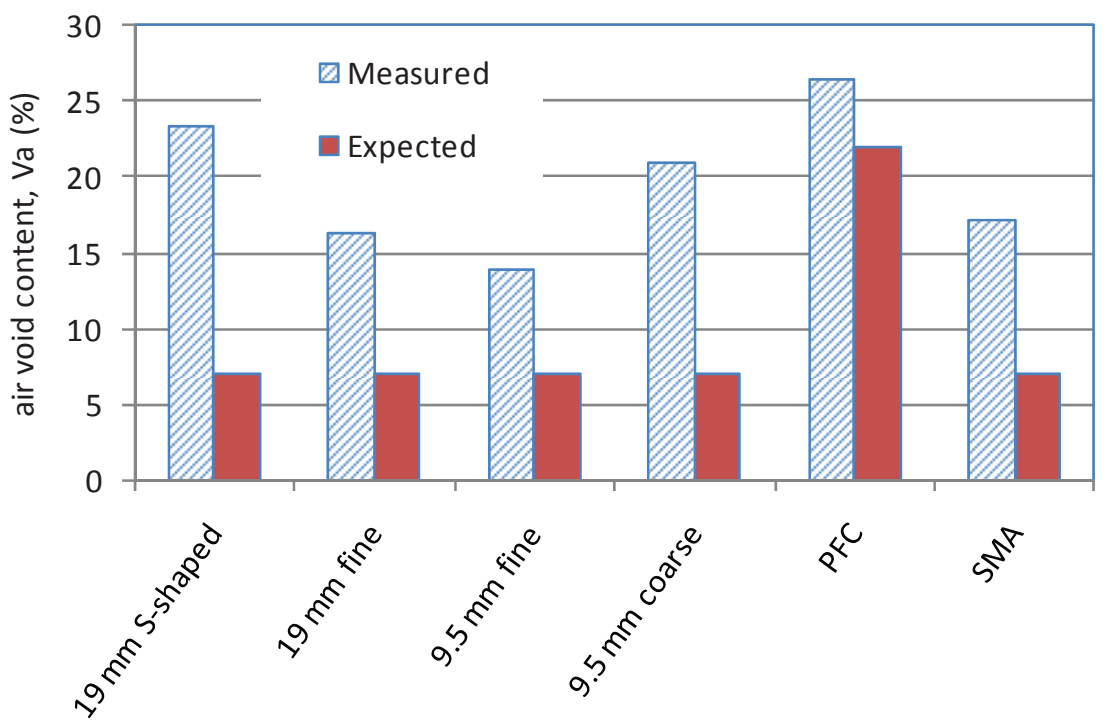

Fig. 5. Expected and measured air void contents

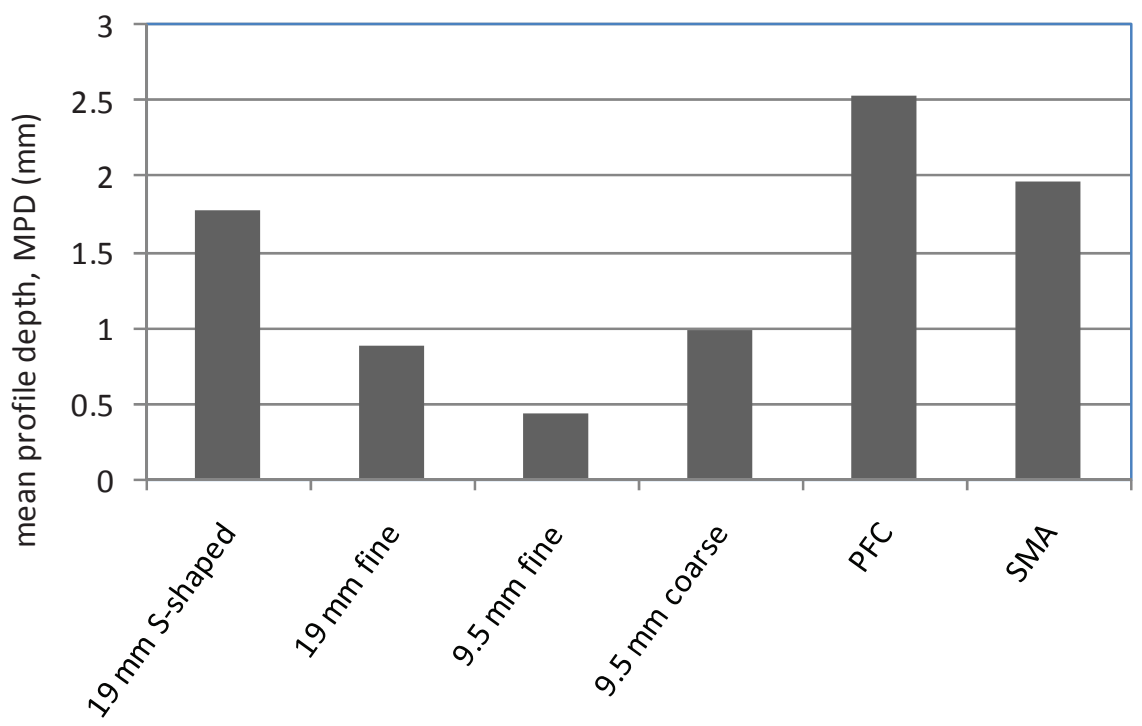

Fig. 6. Mean profile depths 


\subsection{Tire-Pavement Noise Results}

Overall sound intensity levels for all three tires at $48 \mathrm{~km} / \mathrm{h}$ for all six HMA samples are shown in Figure 7. The PFC was loudest for all tires and surface conditions, contrary to expectations and field measurements, followed by the SMA. The four Superpave DGA samples were quieter than both the PFC and SMA, and the 9,5 mm, coarse-graded DGA was the quietest of all. In general, the overall OBSI levels measured with the SRTT did not change significantly between the first two series of tests, as the wearing of the surface was not significant. However, measured OBSI levels increased for all pavements between the second and third series of tests, a reflection of longer wearing times. The Tire B was found to be quieter on all surfaces than the SRTT, while the Tire A was found to be louder than the SRTT; this comparison between the different tires is in agreement with previous measurements made with Portland cement concrete pavement samples on the TPTA (DARE et al. [13]).

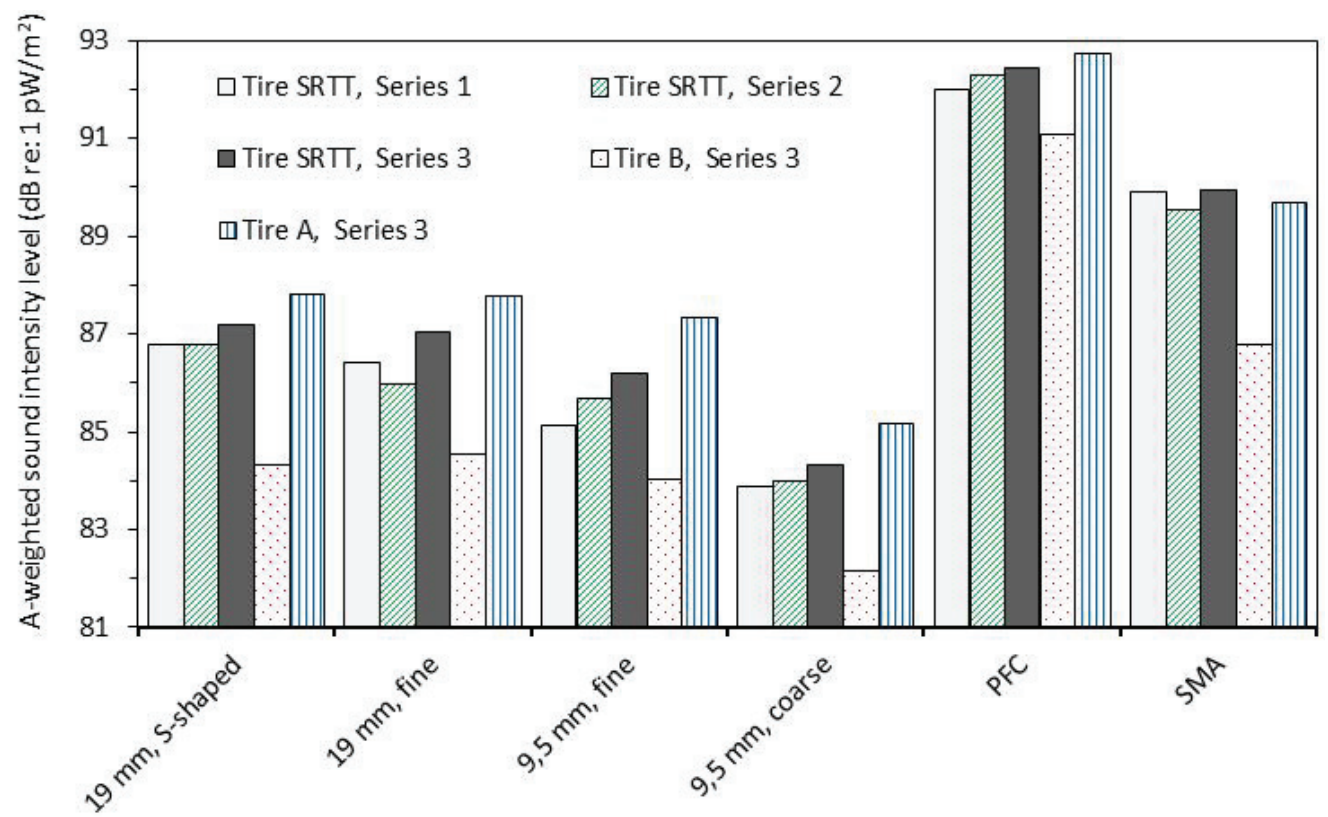

Fig. 7. Overall OBSI levels at $48 \mathrm{~km} / \mathrm{h}$

One-third octave band sound intensity spectra measured with the SRTT at $48 \mathrm{~km} / \mathrm{h}$ during the third series of tests are shown in Figure 8. Similar spectra were measured with the other two tires. For the SMA and the four DGA samples, there is a peak around $800-1000 \mathrm{~Hz}$, while for the PFC the peak is around $500 \mathrm{~Hz}$ and is much higher. This $500 \mathrm{~Hz}$ peak is unusual for tire-pavement noise. It is possible that some roughness features on the PFC sample caused the unexpected peak, though no such features were 
obvious after the compaction process. The sound intensity measured on all samples decreased with frequency above $1250 \mathrm{~Hz}$, though it is interesting to note that the PFC was quieter than most of the other samples at high frequency, despite being substantially louder at low frequencies. In addition, the $9,5 \mathrm{~mm}$, fine-graded DGA sample was the quietest at low frequency (together with the $9,5 \mathrm{~mm}$, coarse-graded DGA), but was among the loudest samples at high frequencies.

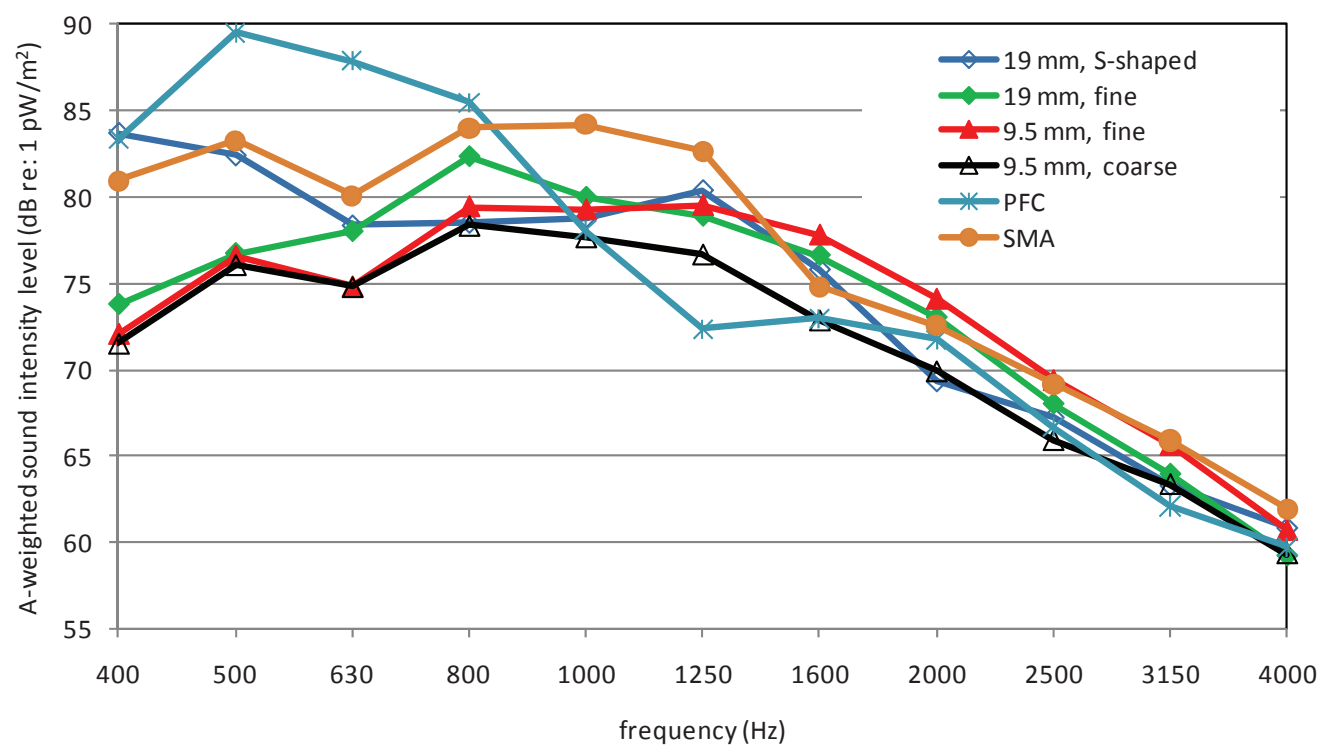

Fig. 8. One-third octave band OBSI spectra measured during third series of tests using SRTT at $48 \mathrm{~km} / \mathrm{h}$

Because of the speed limitations of the TPTA, a logarithmic best-fit curve was used to extrapolate measured data to highway speeds. The OBSI noise level was assumed to vary logarithmically with the speed of the vehicle, as shown in Eq. (4.1).

$$
L=10 a \log _{10}\left(s / s_{r e f}\right)+b
$$

Where:

$L$ is the A-weighted sound intensity level in $\mathrm{dB}$ re: $1 \mathrm{pW} / \mathrm{m}^{2}$,

$s$ is vehicle speed,

$s_{r e f}=1,61 \mathrm{~km} / \mathrm{h}$ is a reference speed,

$a$ and $b$ are parameters determined by the linear least-squares method using data from the three speeds tested.

For all pavement-tire combinations, the speed parameter $a$ was between 3,0 and 4,2, which agrees well with previously-published results for asphalt pavements (Sandberg, 
EjSMONT [9]). The parameter $b$ was between 30 and 42. Equation 1 was then used to extrapolate the measured OBSI data to highway speeds. It should be emphasized that such extrapolations do not represent predictions of measured OBSI levels at highway speeds in the field, but are the best available estimate of the noise levels that might be expected from such testing. Extrapolations to $97 \mathrm{~km} / \mathrm{h}$ are shown in Figure 9. The same trends exist as were discussed for the $48 \mathrm{~km} / \mathrm{h}$ case, with the PFC being the loudest and the $9,5 \mathrm{~mm}$, coarse-graded DGA being the quietest of the pavements tested. Though extrapolations to highway speeds can vary widely with changes in low speed data, it is possible to compare the results of OBSI testing on the TPTA to results of field tests. For example, most asphalt pavements measured at $97 \mathrm{~km} / \mathrm{h}$ with the SRTT have overall OBSI levels of 97-102 dB (Donavan [22]). When compared to these levels, the extrapolated levels from the four DGA pavements tested are lower than typical asphalt pavements, though testing at higher speeds would be necessary before any definitive conclusions could be made.

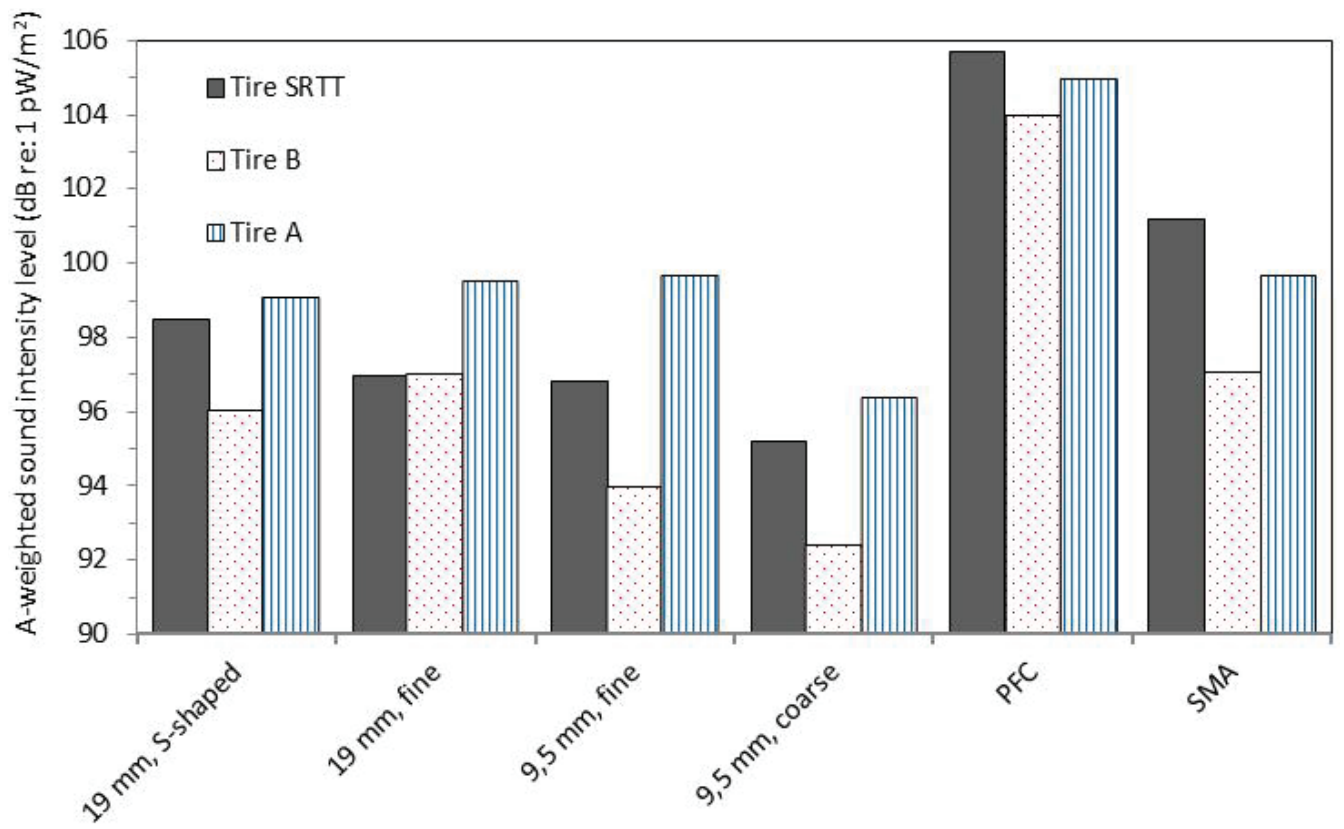

Fig. 9. Overall OBSI levels from series 3 extrapolated to $97 \mathrm{~km} / \mathrm{h}$

It should be noted that these rankings do not agree with field measured noise levels made on the project where the PFC and SMA mixture samples were collected. In the field, controlled pass-by, statistical pass-by and close proximity data all showed the PFC was significantly quieter than the SMA, and both pavements were quieter than a dense graded asphalt pavement (not the same as the mixes evaluated here) (KowALSKI 
et al. [23]). Since the dense graded mixes could not be compacted in the TPTA to the lower air void level achieved in the field, their higher void content is believed to be responsible for the improved noise properties, although detail tortuosity study was not conducted. On the other hand, the level of compaction of the PFC mixes placed in the TPTA was similar to that typically obtained for this kind of mixture in the field.

The quietest surface tested with the TPTA was predicted to produce an A-weighted OBSI level of $96 \mathrm{~dB}$ at highway speeds with the Tire A and Tire B. The same model of tire was used in a large study of asphalt and cement concrete pavements, and measured OBSI levels for asphalt ranged from 95 to $104 \mathrm{~dB}$ (Lodico, ReyfF [24]). The sound levels for the four Superpave samples in this study were quieter than the average of the observed range. Since the samples constructed in this study had higher porosity than the expected values, further investigation into the noise benefits of increased porosity is recommended; in addition, influence of the potential differences in textures can also lead to some differences in noise levels.

\section{Findings, Conclusions and Recommendations for Further Research}

It was shown that laboratory noise testing of HMA using the Tire-Pavement Test Apparatus (TPTA) is feasible. This test method allows to differentiate various asphalt mixtures in terms of their tire-noise generation properties, while noise propagation properties of the pavements cannot be captured due to the test method utilized (OnBoard Sound Intensity). In general, it was found that mixtures with $19 \mathrm{~mm}$ NMAS produced higher noise levels in these TPTA specimens than mixtures with $9,5 \mathrm{~mm}$ NMAS, and that fine-graded mixtures were quieter than both coarse and S-shaped.

Interesting observation was placed on the MPD and noise level. The loudest pavements, the PFC and SMA samples, had the highest measured MPD, while the quietest pavements, the two 9,5 mm DGA samples, had the lowest MPD. These results are in agreement with previous findings about the influence of MPD on measured tire pavement noise (Fujikawa et al. [25], Storeheier [26], Fujikawa et al. [27]). However, MPD has been shown not to be a good predictor of tire-pavement noise at high frequencies, which is further evidenced by the data presented here.

It was found, that because of the limitations of the compaction process, noise results may not be fully indicative of in-service noise levels with representative air void contents. If the compaction process were able to reduce the air void contents to typical field compaction levels, the TPTA would be useful in predicting the influence of HMA mixture composition on tire-pavement noise without the need for building test sections in the field. 


\section{Disclaimer AND AcKnOwledgements}

This work was supported by the Federal Highway Administration and the Joint Transportation Research Program administered by the Indiana Department of Transportation and Purdue University. The contents of this paper reflect the views of the authors, who are responsible for the facts and the accuracy of the data presented herein, and do not necessarily reflect the official views or policies of the Federal Highway Administration and the Indiana Department of Transportation, nor do the contents constitute a standard, specification, or regulation.

The authors wish to express their gratitude to Dr. Ayesha Shah of the North Central Superpave Center at Purdue University as well as Tanya Wulf, Ron Evans and Will Thornton of the Institute for Safe, Quiet and Durable Highways at Purdue University for their assistance during testing and for the in-depth discussions.

\section{REFERENCES}

1. G.G. Fleming, R.E. Armstrong, E. Stusnick, K.D. Polcak, W. Lindenman, Transportation - Related Noise in the United States. Proceedings of the $79^{\text {th }}$ Transportation Research Board Annual Meeting (CD), Washington D.C., January 2000.

2. N.P. Miller, Addressing the Noise from U.S. Transportation Systems; Measures and Countermeasures. TR News, Transportation Research Board, Washington D.C., No. 240, 2005.

3. M. Tracz, J. Bohatкiewicz, Selected problems of noise protection - suggestions of changes in law regulations and strategies [in Polish], TransNoise, Zakopane, 2012.

4. W. Gardziejczyk, Influence o road pavements construction technology and texture on vehicle noise [in Polish], Białystok 2005.

5. A. Kuispers, G. van Blokland, Tyre/road noise models in the last two decades: A critical evaluation. Proceedings of INTER-NOISE, The Hague, 2494, Holland, 2001.

6. S. Taherzadeh, K. Attenborough, Deduction of ground impedance from measurements of excess attenuation spectra. Journal of the Acoustical Society of America, vol. 105, no. 3, 2037-2042, March 1999.

7. T. Inase, K. Kazawa, K. Ishikawa, K. Yoshinisa, Acoustical diagnoses of soundness of porous drainage pavement. Proceedings of INTER-NOISE, 1873, Honolulu, HI, 2006.

8. M.J. Crocker, D. Hanson, Z. Li, R. Karjatkar, K.S. Vissamraju, Measurement of the Acoustical and Mechanical Properties of Porous Road Surfaces and Tire/Road Noise. Transportation Research Record, vol. 1891, 16-22, 2004.

9. U. Sandberg, J.A. Ejsmont, Tyre/Road Noise Reference Book. Informex, Kisa, Sweden, 2002.

10. U. Sandberg, J.A. Ejsmont, Three basic methods for measurement of tire/road noise. Proceedings of INTER-NOISE, 93, Honolulu, HI, 1984.

11. N.A. NiLSSOn, Principles in the control of external tire/road noise. Proceedings of INTER-NOISE, 123, San Francisco, CA, 1982.

12. R.J. Bernhard, W.D. Thornton, J. Baumann, The Effects of Varying the Tire Cap Ply, Sidewall Filler Height and Pavement Surface Texture on Tire/Pavement Noise Generation. Institute for Safe, Quiet and Durable Highways, West Lafayette, IN, Final Report SQDH 2003-1, 2003.

13. T.P. Dare, R.J. Bernhard, W.D. Thornton, Effects of diamond grinding and grooving on tire/pavement noise. Proceedings of Noise-Con 2007, Reno, NV, October 2007. 
14. J. Olek, W.J. Weiss, N. Neithalath, A. Marolf, E. Sell, W. Thornton, Development of Quiet and Durable Porous Portland Cement Paving Materials. Intitute for Safe, Quiet and Durable Highways, West Lafayette, IN, Final Report SQDH 2003-5, 2003.

15. J. Olek, W.J. Weiss, R. Garcia-Villarreal, Relating Surface Texture of Rigid Pavement with Noise and Skid Resistance," Institute for Safe, Quiet and Durable Highways, West Lafayette, IN, Final Report SQDH 2004-1, 2004.

16. L. Scofield, T.J. Smith, Developing Quieter Concrete Pavements, proceedings of the Quiet Pavement Session of the 2006 Annual Conference of the Transportation Association of Canada, Prince Edward Island, 2006.

17. R. Rasmussen, E. Mun, T. Farragut, P. Wiegand, A comprehensive field study on concrete pavement solutions for reducing tire-pavement noise, proceedings of INTER-NOISE, 3898-3909, Honolulu, HI, 2006

18. R. Rasmussen, E. Mun, S. Karamihas, G. Chang, Relating pavement texture to tire-pavement noise, proceedings of INTER-NOISE, 3910-3915, Honolulu, Hawaii, 2006, p.

19. J. Cesbron, F. Anfosso-Ledee, D. Duhamel, H. Ping Yin, D.L. Houedec, Experimental study of tyre/road contact forces in rolling condictions for noise prediction, Journal of Sound and Vibration, vol. 320, no. 1-2, 123-128, February 2009.

20. K.J. Kowalski, R. S. McDaniel, J. Olek, Identification of Laboratory Technique to Optimize Superpave HMA Surface Friction Characteristics, FHWA/IN/JTRP-2010/06. Joint Transportation Research Program, Indiana Department of Transportation and Purdue University, West Lafayette, Indiana, USA, 2010. doi: $10.5703 / 1288284314265$.

21. AASHTO TP 76-09, "Standard Method of Test for Measurement of Tire/Pavement Noise Using the On-Board Sound Intensity (OBSI) Method," Standard Specifications for Transportation Materials and Methods of Sampling and Testing, Washington D.C., 2009

22. P.R. Donavan, The acoustic longevity of various pavements for noise reduction performance based on on-board sound intensity measurements, proceedings of Noise-Con 2010, Baltimore, MD, 2010.

23. K.J. Kowalski, R.S. McDaniel, A. Shah, J. Olek, Long Term Monitoring of the Noise and Frictional Properties of PFC, SMA and DGA Pavements, Transportation Research Record, vol. 2127, 12-19, 2009.

24. D.M. Lodico, J.A. ReYFF, Long-term noise performance of open graded asphalt concrete (OGAC)Results of 10-year long study, Noise Control Engineering Journal, vol. 57, no. 2, 84-93, 2009.

25. J. Fujikawa, Y. Oshino, T. Mikami, H. Tachibana, Examination on effects of road roughness parameters for abating tire/road noise, proceedings of INTER-NOISE, 1120-1125, Prague, Czech Republic, 2004.

26. S.A. STOREHEIER, Investigation on road surface texture levels in tyre/road noise mitigation, proceedings of INTER-NOISE, 3401-3407, Prague, Czech Republic, 2004.

27. T. Fujikawa, Y. Oshino, H. Tachibana, Effect of road roughness on tire/road noise - Approach by frequency analysis, proceedings of INTER-NOISE, 706-710, Istanbul, Turkey, 2007. 